\title{
Perfume de mulher: a adaptação teatral brasileira a partir das obras cinematográficas de Dino Risi e Martin Brest
}

\section{Scent of a Woman: The Brazilian theatrical adaptation from the films of Dino Risi and Martin Brest}

Paulo Edson Alves Filho*

Juliana Hass ${ }^{* *}$

* Docente do curso de Letras da Universidade de Sorocaba - UNISO. Doutor em Língua Inglesa e Literaturas Inglesa e Norte-americana pela FFLCH/USP. E-mail: paulo.alves@prof.uniso.br

"Doutora em Letras (Língua e Literatura Italiana) pela Universidade de São Paulo e pós-doutoranda na mesma instituição. E-mail: juliana.hass@usp.br

TradTerm, São Paulo, v.38, fevereiro/2021, p. 272-290

Número Especial - III JOTA

www. revistas.usp.br/tradterm 
Resumo: Perfume de Mulher, comédia dramática baseada nos filmes Profumo di Donna, de Dino Risi (1974) - protagonizado por Vittorio Gassman - e Scent of a Woman, de Martin Brest (1992) - pelo qual Al Pacino recebeu o Oscar de melhor ator, teve a versão teatral brasileira escrita por Silvio Guindane, Pedro Brício e Walter Lima Jr. Neste trabalho analisaremos os elementos da adaptação brasileira à luz das teorias dos Estudos da Adaptação como as de Linda Hutcheon (2006), Julie Sanders (2006), e outros estudiosos do assunto. Discorreremos sobre o diálogo entre cinema e teatro, buscando destacar as características específicas de cada mídia e o ponto de vista de seus respectivos autores, por meio dos recursos utilizados nas linguagens literária, cinematográfica e teatral.

Palavras-chave: Adaptação; Il Buio e il Miele; Profumo di Donna de Dino Risi; Scent of a Woman de Martin Brest; Perfume de Mulher peça de Silvio Guindane, Pedro Brício e Walter Lima Jr.

Abstract: Perfume de Mulher, a dramatic comedy based on the films Profumo di Donna by Dino Risi (1974) - starring Vittorio Gassman - and Scent of Woman, by Martin Brest (1992) - for which Al Pacino won the Oscar as best actor, had the Brazilian stage version written by Silvio Guindane, Pedro Brício and Walter Lima Jr. In this work we will analyze the elements of the Brazilian adaptation under the theories of Adaptation Studies such as of Linda Hutcheon (2013), Julie Sanders (2006) among other scholars. We will discuss the dialogue between cinema and theater, seeking to highlight the specific features of each media and the point of view of their respective authors as well as the resources they used in the literary, cinematographic and theatrical versions.

Keywords: Adaptation; Il Buio e il Miele; Profumo di Donna by Dino Risi; Scent of a Woman by Martin Brest; Perfume de Mulher, a play by Silvio Guindane, Pedro Brício and Walter Lima Jr.

TradTerm, São Paulo, v.38, fevereiro/2021, p. 272-290

Número Especial - III JOTA

www.revistas.usp.br/tradterm 


\section{Introdução}

Cinco anos após sua publicação (1969), o romance ll buio e il miele, de Giovanni Arpino (1927-1987), foi adaptado por Dino Risi para o cinema como Profumo di donna, obtendo grande sucesso de crítica e de público. Em 1992, o filme foi readaptado por Martin Brest e estreado como Scent of a Woman, conquistando, igualmente, seus críticos e público. Posteriormente, em 2019, celebrando, portanto, 50 anos da publicação do romance, Silvio Guindane, Pedro Brício e Walter Lima Jr., baseados no livro e nos dois filmes, fizeram uma adaptação para o teatro intitulada Perfume de mulher.

Thaïs Diniz, em seu Literatura e Cinema - da Semiótica à Tradução Cultural (1999), afirma que uma obra fílmica resultante de tradução intersemiótica a partir de qualquer arte dispõe de recursos que vão além de imagens (signos em operação), tais como: o trabalho da câmera, os planos estáticos (de conjunto, médio e primeiro plano), planos panorâmico, com movimento, acelerado ou lento. Acrescente-se, ainda, a dissolvência, fusão de imagem, divisões de tela, montagem e uso da sucessão rítmica de imagens, que não são percebidos isoladamente, mas como partes de um todo orgânico interativo (DINIZ 1999: 72).

Mullin (apud DiNIZ 1999: 75-76), por sua vez, nota que podem ocorrer diferentes transferências entre uma peça adaptada ao cinema, além de cenários, da interpretação dos atores e da estilização, em que o tradutor/adaptador "escolhe modificar uma situação, reduzindo-a ou ampliando-a", dependendo de sua intenção em relação à audiência.

A partir da perspectiva reversa das observações dos autores, tomaremos como objeto de estudo a adaptação teatral brasileira Perfume de Mulher (2019), destacando as características da obra teatral e suas relações com as obras cinematográficas originais.

TradTerm, São Paulo, v.38, fevereiro/2021, p. 272-290

Número Especial - III JOTA

www.revistas.usp.br/tradterm 


\section{Il Buio e il Miele, de Giovanni Arpino}

Publicado em 1969 (tradução brasileira A Escuridão e o Mel, Berlendis; Vertecchia, 2001) e vencedor do Prêmio Marino Moretti D'Oro, Il Buio e il Miele conta a história do ex-oficial do exército, Fausto G., que ficou cego e incapacitado devido à explosão acidental de uma granada. No mesmo acidente, o tenente Vincenzo C., que reside em Nápoles, também perdeu a visão. Fausto, que vive em Turim com uma tia idosa, decidiu visitar seu amigo e embarca em uma viagem de uma semana, passando por Gênova, Roma até chegar a Nápoles. Para acompanhá-lo, contrata um jovem estudante (apelidado Ciccio), que está prestando serviço militar; o jovem, voz narrativa da história, logo perceberá quão pesada e ingrata é a tarefa. 0 oficial, de fato, macerado pelos problemas e medos que tenta em vão esconder, pretende suicidar-se.

Ciccio se encontra, assim, sendo mera testemunha da história, enquanto a figura de Fausto $G$. se destaca por toda a sua força expressiva e complexidade de posturas e estados de ânimo. Nele, poderíamos dizer, estão vários vícios humanos, que oscilam entre desprezo pelo perigo, covardia e mesquinhez cotidiana. A natureza excepcional desse caráter é o ponto forte da obra: Fausto G. controla e dirige os outros personagens, coordena ações e pensamentos como um marionetista, reduzindo-os a figuras coadjuvantes.

O livro tem um ritmo premente, marcado por diálogos rápidos - já predisposto, portanto, a ser traduzido para a linguagem cinematográfica - que levam a um final inesperado. 0 pessimismo, que percorre toda obra, desaparece inesperadamente nas páginas finais, quando a iminência da tragédia se torna ocasião para um recomeço: o misantropo Fausto G. rende-se ao amor.

0 título original refere-se à cegueira e ao amor, derivado da epígrafe do poeta Rainer Maria Rilke. Outra interpretação, porém, pode aludir às características da dupla: um amargo militar e seu inexperiente e jovem acompanhante.

Segundo Nicole Bahbout, crítica de cinema do The Guardian, o relacionamento que se desenvolve entre o militar experiente e o jovem soldado é construído mais

TradTerm, São Paulo, v.38, fevereiro/2021, p. 272-290

Número Especial - III JOTA

www. revistas.usp.br/tradterm 
sobre a realidade brutal do que quaisquer noções de amizade ou lealdade. Sua jornada pela Itália evoca, ironicamente, um épico homérico, tendo Fausto como seu anti-herói bêbado, anunciando alegremente sua própria condenação a cada passo do caminho. Arpino é inflexível nas complexidades de seus personagens. Trata o assunto da cegueira com franqueza não sentimental e seu hábil senso de humor e lampejos de ternura resgatam o livro da angústia existencial. A eventual rendição de Fausto ao amor e à confiança é uma derrota trágica. 0 romance, em última análise, resiste à explicação tanto quanto adia seu destino, com a linha final questionando o ato da representação em si (BAHBOUT 2011).

Deste romance foram adaptados dois filmes: Profumo di Donna, 1974, de Dino Risi, com Vittorio Gassman no papel de protagonista, e Scent of a Woman, 1992, de Martin Brest, interpretado por Al Pacino.

\section{Profumo di Donna de Dino Risi, 1974.}

Risi coloca suas obras dentro de um discurso que visa dar voz aos desesperados e desiludidos. Com Risi, a comédia italiana assume ares de tristeza e angústia, porém, confortando o espectador com felizes fins românticos. 0 gênero cômico, experimentado pelo diretor milanês, atinge essa qualidade que o torna um filão cinematográfico agridoce. São filmes pertencentes a essa tendência, caracterizados por certo anseio, além da risada, conseguindo operar uma forma de entretenimento capaz de falar com vários públicos, obtendo um enorme sucesso nacional e internacional. Autores como Risi, Monicelli e outros contribuíram para dar origem a esse gênero estritamente italiano, reafirmando a popularidade incontestável do gênero em todo o mundo, com enorme sucesso de público e de crítica da época. $E$ ter sido objeto de remake, em 1992, por Martin Brest, com a colaboração de Al Pacino para assumir o papel de protagonista. Profumo di donna também é o melhor exemplo do cinema risiano, bem como a melhor colaboração do diretor com o ator Vittorio Gassman. 0 filme é baseado quase inteiramente em sua interpretação extraordinária.

TradTerm, São Paulo, v.38, fevereiro/2021, p. 272-290

Número Especial - III JOTA

www. revistas.usp.br/tradterm 
Gassman recebeu, com razão, o prêmio de melhor interpretação masculina no Festival de Cannes de 1975.

Gassman interpreta papel de Fausto Consolo, capitão aposentado do exército italiano. Devido a um acidente, ele perdeu a visão e a mão esquerda. Risi constrói seu personagem de maneira nervosa e incisiva. Um homem corroído na alma pela frustração devido à sua cegueira e ao sentimento de piedade transmitido a ele pelas pessoas ao seu redor. Um homem que, com maldade, procura sob todos os pretextos uma possibilidade de redenção com o mundo. A sátira do filme assume, então, tons acres e sombrios. O espectador é capaz de perceber todo o sofrimento e a dor silenciosa de um homem que tenta lutar com seu próprio desconforto, cuja pior característica é a impossibilidade de poder ver e admirar a beleza dos corpos femininos.

$\mathrm{Na}$ viagem com o jovem recruta Giovanni Bertazzi existem momentos de diversão e descontração devido à relação entre os dois personagens masculinos.

Figura 1: cenas do filme Profumo di donna de Dino Risi (1974)
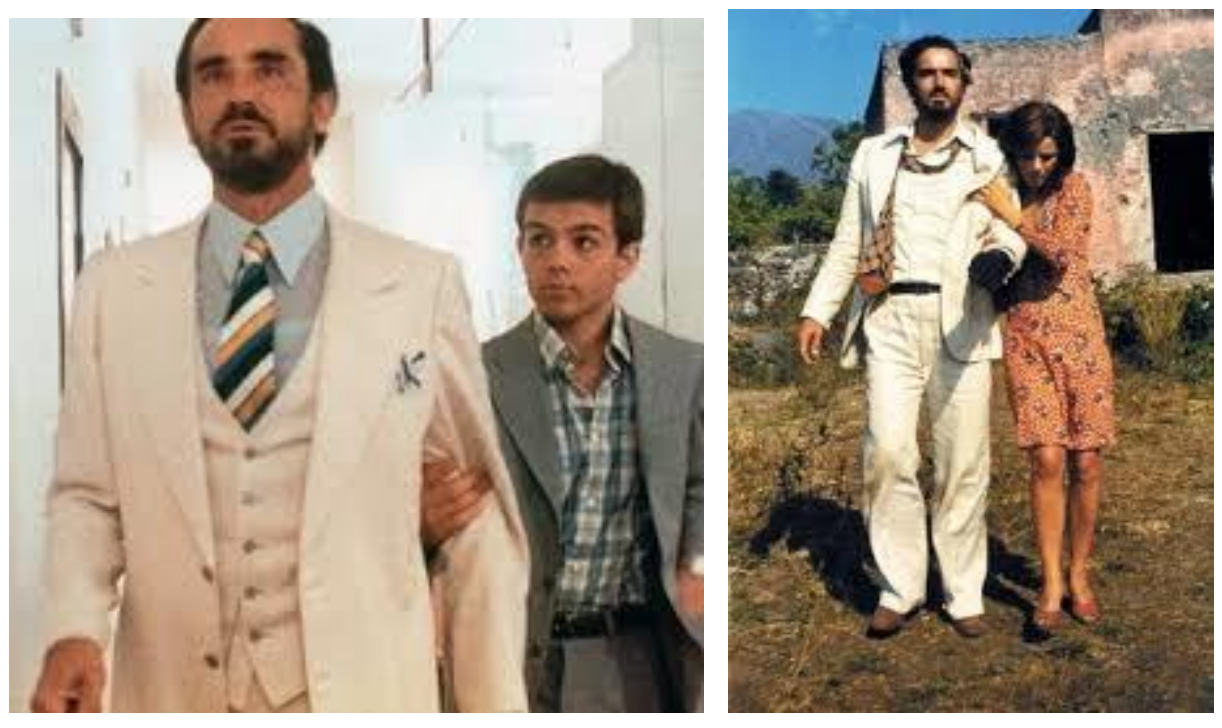

Gênova e Roma são etapas desta fatídica jornada, tanto em nível concreto quanto aparentemente simbólico. As paradas nas duas cidades tornam-se momentos significativos, se enquadrados na perspectiva determinística da viagem, cujo objetivo

TradTerm, São Paulo, v.38, fevereiro/2021, p. 272-290

Número Especial - III JOTA

www. revistas.usp.br/tradterm 
é chegar a Nápoles e cometer suicídio junto a seu amigo Vincenzo. Então, podemos considerar os estágios da viagem como símbolos de aceitação e consolo no caminho para a morte. Em Gênova, o capitão Consolo decide ter sua última relação sexual com uma mulher, uma prostituta, enquanto em Roma ele busca a bênção de seu primo padre, para obter absolvição espiritual pelo pecado que irá cometer.

Chegando a Nápoles, o capitão encontrará a jovem Sara, apaixonada por ele de maneira não correspondida. Aqui também encontramos um ponto sensível na história. 0 amor não correspondido se deve à frustração do protagonista, que não quer condenar a jovem a um destino amargo em sua companhia. Ao qual, no entanto, cederá após a fracassada tentativa de suicídio. O capitão Consolo, chocado com o evento, passa a ter plena consciência de sua condição, aceitando-a.

\section{Scent of a Woman, de Michael Brest, 1992.}

A versão americana, do diretor Michael Brest, lançada em 1992, apresenta roteiro diverso do filme de Risi e, consequentemente, da história de Arpino.

A história é centrada no aluno universitário Charlie Simms (interpretado por Chris O'Donnell) durante o período de Ação de Graças. Charlie, ao contrário de seus colegas de classe privilegiados, não tendo possibilidades financeiras de voltar à sua casa e celebrar com a família, ao ver um anúncio solicitando acompanhante a um cego, decide se candidatar, pois o pagamento the seria útil para voltar a casa no Natal. O cego é um coronel da reserva que vive nos fundos da casa da sobrinha que passa seu tempo entre uísque e charutos.

O coronel Slade (interpretado por Al Pacino) é zangado e sarcástico, preso em sua cegueira, com um humor amargo. Na versão americana há, também, uma trama secundária que aflorará ao fim da história: Charlie tem problemas onde estuda, pois foi testemunha de uma brincadeira feita por outros colegas que danificou o carro do diretor de sua escola. Nos dias seguintes ele participará de uma audiência disciplinar e poderá delatar os alunos envolvidos. Charlie acredita que passaria o fim de semana na residência do coronel, acompanhando-o em rodadas de bebida e ouvindo seus

TradTerm, São Paulo, v.38, fevereiro/2021, p. 272-290

Número Especial - III JOTA

www.revistas.usp.br/tradterm 
insultos. Contudo, Slade tem outras intenções: compra passagens para Nova York e informa o jovem que ele o acompanhará. Ao longo da jornada, Slade tenta doutrinar Charlie sobre suas concepções sobre mulheres, muitas vezes antiquada, em um misto de desejo e fascínio, adequadas a alguém que viveu toda uma vida militar. Ele afirma que pode inalar o perfume de uma mulher e, a partir dele, adivinhar suas características físicas, tais como a cor dos cabelos ou a dos olhos.

Ao longo da história, o coronel não abandona o álcool, prática que Charlie vê com crescente alarme. A relação entre o velho e o jovem é por vezes leve, mas predominantemente tensa. Charlie tenta manter distância dos arroubos do coronel, temendo o que pode acontecer a ambos com suas atitudes inconsequentes. Em Nova lorque, alugam uma Ferrari e ficam hospedados no caríssimo hotel Waldorf. Em uma casa noturna, o coronel dança tango com uma jovem, enquanto Charlie lança olhos interessados nela. Charlie o aguarda em um táxi enquanto ele visita uma prostituta. 0 ápice da tensão entre os dois acontece quando Charlie sabota sua tentativa de suicídio na suíte do hotel e pede para que o coronel também atire nele se ele quiser levar seu plano mortal adiante, o que não acontece. Ao final, há o desenlace do problema de Charlie na escola na qual o coronel Slade desenvolve papel crucial para sua resolução.

Figura 2: Cenas do filme Scent a of Woman, de Michael Brest (1992)

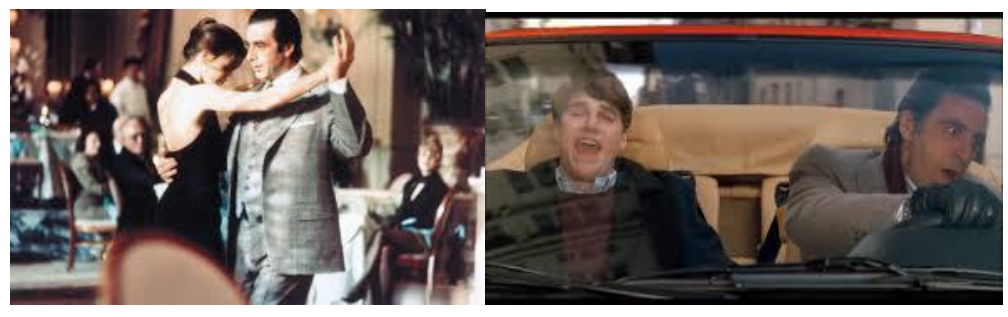

0 enredo americano difere substancialmente do italiano, em especial ao personagem que acompanha o cego. Em artigo do Corriere della Sera, o próprio diretor italiano diz que se trata de outra história e que a versão americana "falhou" (Corriere della Sera, 16 de maio de 1993).

TradTerm, São Paulo, v.38, fevereiro/2021, p. 272-290

Número Especial - III JOTA

www.revistas.usp.br/tradterm 
Segundo o jornalista Fabio Mandagli (Civico20news), o personagem de Gassman é decididamente mais original e humano, portador de contradições em sua relação de amor e indiferença com a bela Sara (Agostina Belli), a jovem amiga de família que se entregaria de corpo e alma, mas que ele rejeita convencido de que ela não o mereça. Por outro lado, afirma o autor, Al Pacino ostenta um caráter mais exagerado e explosivo.

O crítico nota, ainda, que há uma diferença também nos atores coadjuvantes que interpretam o guia do cego. Na versão americana, temos um Charlie mais angelical e inexperiente, encarnado por Chris O'Donnell, em comparação com o mais inteligente e travesso Ciccio, interpretado por Alessandro Momo, que no ano anterior protagonizara um adolescente com hormônios em ebulição no convívio com a governanta Angela (Laura Antonelli), no filme cult erótico Malizia (Salvatore Samperi, 1973).

Assim, o autor conclui que Brest embala a adaptação de modo elegante e com um bom ritmo que agrada o público americano, mas Risi certamente se mostra superior em tudo, com uma direção mais humana, com personagens e locais perfeitamente reconhecíveis no ecossistema do território italiano.

Claus Cluver (1997: 45) observa que adaptação, quando se refere a peças teatrais ou cinematográficas, implica em um ajuste ao novo meio, que ele chama de transposição intersemiótica ou reelaboração livre.

Essa reelaboração, segundo a ótica de Mandagli, ao afirmar que a versão americana atende às expectativas dos americanos (em detrimento de paragens e personagens reconhecidos no território italiano), pode estar relacionada à noção de localização enquanto conceito teórico. Esser (2016: 21) relaciona localização à construção de uma cultura nacional como algo social e culturalmente construído, imaginado ou inventado. Concluímos, portanto, que parte da boa aceitação do filme de Brest nos Estados Unidos deva-se ao fato de o público americano identificar como familiares situações e paragens em sua obra.

Vale notar também que o texto de Arpino teve uma terceira adaptação cinematográfica, a egípcia Amir El Zalam (Rami Imam, 2002), que narra a história de

TradTerm, São Paulo, v.38, fevereiro/2021, p. 272-290

Número Especial - III JOTA

www. revistas.usp.br/tradterm 
um oficial que perdeu a visão na guerra de Yom Kippur e lidera um grupo de jovens também cegos. A trama difere drasticamente das versões de Risi e Brest, tendo contornos nacionalistas, os quais também sinalizam o processo de localização em sua elaboração.

\section{Perfume de mulher, Silvio Guindane, Pedro Brício e Walter Lima Jr., 2019.}

Em uma entrevista1 concedida ao "Mala Cultural", Silvio Guindane disse que a ideia de trazer Perfume de Mulher para os palcos surgiu quando estava em Portugal, fazendo o espetáculo A confissão, produzido por ele e dirigido por Walter Lima Jr. Conversando, Lima comentou que Perfume de Mulher daria uma boa peça. O motivo pelo qual Guindane comprou os direitos autorais para trazer essa história para os palcos foi, segundo o diretor e protagonista da peça, o fato de, atualmente, "as pessoas estarem muito sozinhas, cada vez mais individualistas, não largarem o celular, estarem pensando em si o tempo inteiro, ficarem brigando para conseguir sobreviver em meio a tanta individualidade". Para ele, a história encenada é exatamente o contrário, são duas pessoas que conseguem se olhar, se compreender de verdade e, a partir disso, transformar suas vidas. 0 trabalho de Ciccio poderia ser completamente servil, mas ele percebe algo e acaba mudando a vida do cego; um quer viver e o outro morrer e os dois se transformam durante a viagem.

Baseado no livro e nos dois filmes, Silvio Guindane, Pedro Brício e Walter Lima Jr. fizeram a adaptação para o teatro. Segundo Guindane, na mesma entrevista, os adaptadores não se preocuparam com os filmes, justamente para evitar comparação, mas trouxeram alguns de seus componentes e, paralelo a isso, trabalharam e ensaiaram para conseguir juntar elementos interessantes e trazê-los para o palco de uma maneira que o público aceitasse. No filme americano Sara não existe, mas existe no livro e também no filme italiano. Gabriela Duarte afirma que a personagem da peça foi criada por Walter, Silvio e Pedro Brício, que adaptaram o texto; uma personagem, de acordo com Duarte, que entrou com mais força do que talvez tenha

\footnotetext{
${ }^{1}$ https://www.youtube.com/watch?v=zYuKGfq_F5k. Acesso: 20/01/2021.

TradTerm, São Paulo, v.38, fevereiro/2021, p. 272-290

Número Especial - III JOTA

www.revistas.usp.br/tradterm
} 
realmente, tanto no livro quanto no filme italiano. E, segundo a atriz, para ela foi bom, porque teve certa liberdade para criar sua Sara, sem se basear muito nos filmes.

O motivo de compararmos o romance, os dois filmes e a peça teatral serve para entender o processo de adaptação para o teatro e não para examinar a 'fidelidade' entre as obras, pois concordamos com Robert Stam (2000) que, ao analisar adaptações da literatura para o cinema, tece comentários apropriados sobre 'adaptação $x$ fidelidade'. No nosso caso, interessa quando o autor afirma que o leitor da obra literária considera a adaptação aquém do texto fonte e, portanto, 'infiel', justamente por não identificar na história narrada aquilo que julgou importante ou bem trabalhado no livro, no ponto de vista dele.

Porém, segundo Stam é difícil considerar 'fidelidade' uma categoria justa para criticar uma adaptação quando há mudança de um meio para outro, pois os meios são diferentes. Assim, propõe que, em vez de considerar adaptações como secundárias ao texto de partida, sejam consideradas novas obras, oriundas de um processo criativo, e que o processo de adaptação seja visto como um 'dialogismo intertextual'.

Talvez por isso - pela dificuldade de se entender o processo de adaptação, ou de se percebê-lo - a adaptação como uma nova obra que, apesar de estar interligada ao texto fonte, seja uma criação autônoma.

Fig. 3. Cenas da adaptação teatral brasileira Perfume de Mulher (2017)

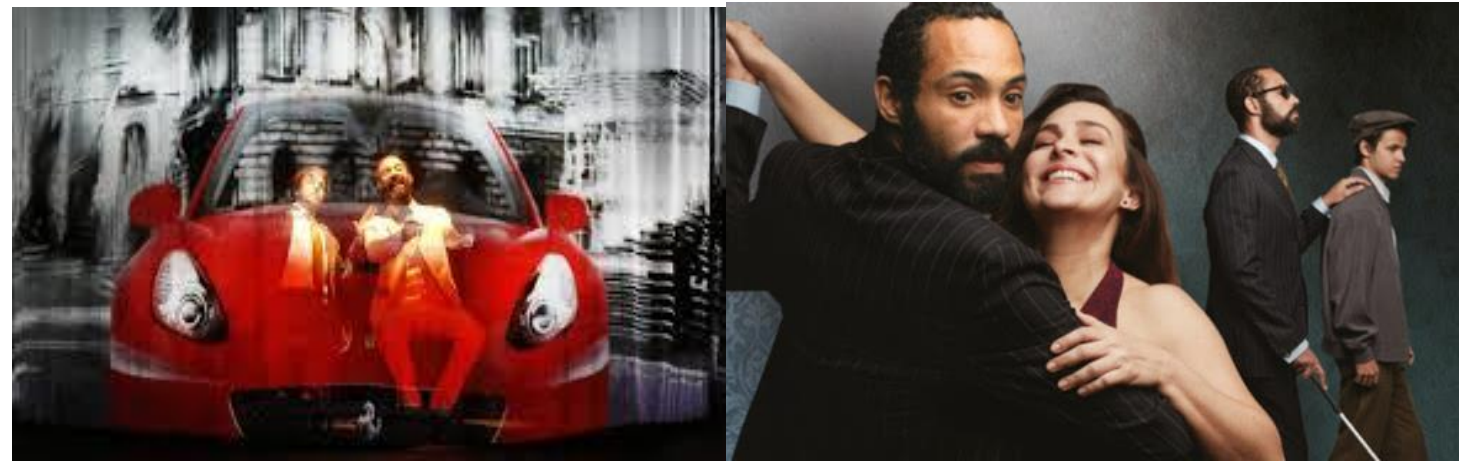

De acordo com Roman Jakobson (1969: 63-64), o signo verbal pode ser interpretado por meio da tradução para outros signos da mesma língua (intralingual TradTerm, São Paulo, v.38, fevereiro/2021, p. 272-290 Número Especial - III JOTA www.revistas.usp.br/tradterm 
ou reformulação), para outros signos de outra língua (interlingual ou tradução propriamente dita) e para outro sistema de signos não-verbais (intersemiótica ou transmutação); mediante contexto linguístico que nos auxilia a interpretar os sentidos, o significado é produzido. Baseando-nos nessa categorização, podemos dizer que os adaptadores, primeiramente, interpretaram o romance e os filmes por meio da "reformulação" - componente do processo de adaptação -, passando-os para a linguagem dramática; o texto dramático, por sua vez, passou por uma "transmutação" quando encenado.

Segundo Jakobson (1969: 63-64), tradução intersemiótica - ou transmutação - é o processo de "interpretação dos signos verbais por meio de sistemas de signos nãoverbais", ou melhor, é a "transposição inter-semiótica de um sistema de signos para outro, por exemplo, da arte verbal para a música, a dança, o cinema ou a pintura" (JAKOBSON, 1969: 71) e, ainda, para o teatro, como no nosso caso. Assim, os adaptadores ressignificaram as mensagens do romance e dos filmes para que pudessem ser transmitidas no teatro. Tal ressignificação foi determinada pelo sistema de signos da encenação, produzindo significado para o espectador; também ressignificaram os signos da encenação inserindo elementos fílmicos, por meio do videowall, no palco e essa ressignificação foi determinada pelo sistema de signos do cinema (projeção, efeitos sonoros, iluminação), produzindo significado para a plateia. Em outras palavras, a tradução intersemiótica da obra literária e dos filmes para o teatro se deu mediante as palavras, gestos e movimentos dos personagens que agem na cena; o cenário; o figurino; o videowall, a música, os efeitos sonoros, a iluminação, etc. que interpretam os signos verbais do romance e dos filmes.

Aqui, é interessante ressaltar a afirmação de Kattenbelt (2008: 20-23) de que a inclusão de vídeo na peça teatral evidencia sua capacidade de incorporar todas as mídias, fazendo com que ele possa ser considerado uma hipermídia, ou seja, uma mídia que contém todas as outras. A multimidialidade, ou a combinação de diferentes mídias, não danifica suas respectivas especificidades ou materialidade. A autora nota, também, que um processo de teatralização ocorre quando duas ou mais formas de artes se juntam.

TradTerm, São Paulo, v.38, fevereiro/2021, p. 272-290

Número Especial - III JOTA

www. revistas.usp.br/tradterm 
Julio Plaza (2003: 89), seguindo Jakobson e "em correspondência com o mesmo espírito que guia a organização das tipologias de signos formuladas por Pierce", mostra as traduções como icônicas - pautadas "pelo princípio de similaridade de estrutura" -, indiciais - "entre o original e tradução" - ou simbólicas - "pela contiguidade instituída, o que é feito através de metáforas, símbolos ou outros signos de caráter convencional” (2003: 89-93).

Afirma, ainda, que o texto fonte é objeto da obra nele modelada e, por ser signo daquele texto, conserva com ele certa relação, por exemplo, quando o romance e os filmes são adaptados para o teatro, como no nosso caso, ocorre a formação de um novo tipo de signo que depende tanto do espetáculo teatral quanto da linguagem verbal e fílmica para ter significado. Segundo Plaza, as traduções são semioses e a tradução intersemiótica é uma semiose com mudança de matéria. 0 teatro, como desempenho, representa atividades semióticas que existem para significar. Se tivermos um romance (para ser lido), dois filmes (para serem assistidos e ouvidos) e um espetáculo teatral (para ser assistido e ouvido), sendo um signo icônico do outro, logo um é a transmutação - ou tradução - intersemiótica do outro.

O processo de tradução consiste na procura de equivalência entre os sistemas: um dado elemento, que ocupa determinado lugar no romance, é substituído, durante o ato tradutório, por outro elemento que exercerá a mesma função no texto dramático. Por sua vez, alguma coisa que toma certa posição no texto dramático será trocada, no processo de tradução, por outra coisa que desempenhará função análoga, mas em um sistema de signos diferente, a encenação (espetáculo). Igualmente, um dado elemento, que ocupa determinado lugar nos filmes, é substituído, durante o ato tradutório, por outro elemento que exercerá a mesma função no texto dramático. No entanto, alguma coisa que toma certa posição no texto dramático será trocada, no processo de tradução, por outra coisa que desempenhará função análoga, mas em um sistema de signos diferente, o teatro (representação da peça). A equivalência é, portanto, uma dialética entre os signos do romance, dos filmes, do texto dramático e do espetáculo.

TradTerm, São Paulo, v.38, fevereiro/2021, p. 272-290

Número Especial - III JOTA

www. revistas.usp.br/tradterm 
Em "Interpretar não é traduzir", de seu livro Dire quase la stessa cosa. Esperienze di traduzione, Umberto Eco (2007) afirma que "O universo da interpretação é mais amplo daquele da tradução propriamente dita"2 (Eco, 2007: 234). Importante notar que, para o autor, a interpretação deve preceder a tradução, inclusive a semiótica, e transmutação tem sentido de mudança de sistema semiótico. Eco também considera a "transmutação de matéria acrescenta significados, ou torna relevantes conotações que originalmente não o eram" 3 (idem, itálico do autor) e que a "adaptação sempre constitui uma tomada de posição crítica - mesmo se inconsciente, mesmo se devida à imperícia ao invés da escolha interpretativa consciente" ${ }^{4}$ (2007: 336, itálico do autor).

0 processo de significação e de produção de significados é muito rico e, por isso, existem muitas possibilidades de interpretação. A análise e as escolhas utilizadas pelo adaptador são apenas uma dentre as várias alternativas possíveis, portanto, outras análises e escolhas completamente diferentes poderiam ter sido feitas.

Patrice Pavis (2008), por sua vez, define adaptação como "transposição ou transformação de uma obra, de um gênero em outro"; no caso da transposição do romance e dos filmes para peça, é sinônimo de dramatização, ou seja, "adaptação de um texto e dois filmes para [...] um material destinado ao palco" e "operação semiótica de transferência", na qual o romance e os filmes são transpostos "em ações cênicas que usam todas as matérias da representação teatral (gestos, imagens, música etc.)"; como sentido de "trabalho dramatúrgico a partir do texto destinado a ser encenado"; por fim, como “'tradução' ou de transposição [...], sem que seja sempre fácil traçar a fronteira entre as duas práticas”, ou seja, é "uma tradução que adapta o texto de partida ao novo contexto de sua recepção com as supressões e acréscimos julgados necessários à sua reavaliação". Para Pavis (2008: 10-11), a adaptação é "uma recriação, $[. .$.$] a transferência das formas de um gênero para outro nunca é inocente,$ e sim [...] implica a produção do sentido".

2 L'universo dell'interpretazione è più vasto di quello della traduzione propriamente detta.

${ }^{3}$ [...] la trasmutazione di materia aggiunga significati, o renda rilevanti connotazioni che non erano originalmente tali.

${ }^{4}$ L'adattamento costituisce sempre una presa di posizione critica - anche se incosciente, anche se dovuta a imperizia piuttosto che a scelta interpretativa consapevole.

TradTerm, São Paulo, v.38, fevereiro/2021, p. 272-290

Número Especial - III JOTA

www.revistas.usp.br/tradterm 
O autor (2008: 10) afirma que, ao adaptar:

[...] todas as manobras textuais imagináveis são permitidas: cortes, reorganização da narrativa, "abrandamentos" estilísticos, redução do número de personagens ou dos lugares, concentração dramática em alguns momentos fortes, acréscimos e textos externos, montagem e colagem de elementos alheios, modificação da conclusão, modificação da fábula em função do discurso da encenação. A adaptação, diferentemente da tradução ou da atualização, goza de grande liberdade; ela não receia modificar o sentido da obra original, de fazê-la dizer o contrário [...]. Adaptar é recriar inteiramente o texto, considerado como simples matéria [...].

Nesse sentido, Loretta Innocenti (2010: 37) afirma que as "modalidades pelas quais o segundo texto [adaptação] utiliza elementos do primeiro texto [fonte], para criar a própria coerência interna, podem ser reduzidas a quatro mecanismos lógicos básicos” enumerados da seguinte maneira: “1) a redução [...]; 2) a amplificação [...]; 3) a transformação ou substituição [...]; 4) a interpolação [...]" 5 .

Segundo Innocenti (2010: 41), a redução acontece quando "o primeiro texto é usado parcialmente, com omissão de certos trechos considerados não mais pertinentes ou, pelo menos, eficazes para a compreensão do sentido da obra: uma espécie de subtração" e continua afirmando ser "uma prática comum no teatro; mesmo quando o texto é considerado sagrado e intocável, todas as suas encenações cortam algumas partes, reduzindo-o por razões de duração e de tempo". ${ }^{6}$ Somente no palco é possível perceber as "partes consideradas essenciais para o sentido [do espetáculo] e partes acessórias, que são sentidas como diferimentos ou digressões inapropriadas".

Innocenti (2010) define amplificação o processo pelo qual elementos não presentes no texto fonte são, ao contrário da redução, inseridos na adaptação; esses elementos podem, inclusive, ser reconhecidos, no nosso caso, pelos espectadores. É o

\footnotetext{
${ }^{5}$ Le modalità con cui il testo secondo utilizza elementi del testo primo, per creare la propria coerenza interna, si possono ridurre a quattro basilari meccanismi logici: 1) la riduzione, [...]; 2) l'amplificazione, [...]; 3) la trasformazione, o sostituzione, [...]; 4) l'interpolazione [...].

${ }^{6}$ [...] il testo primo viene utilizzato parzialmente, con l'omissione di certi tratti non ritenuti più pertinenti o per lo meno efficaci per la comprensione del senso dell'opera: una specie di sottrazione. [...]. La riduzione è una pratica comune a teatro; anche quando il testo sia considerato sacro e intoccabile, ogni sua messa in scena taglia delle parti, lo riduce per ragioni di lunghezza e di tempo.

TradTerm, São Paulo, v.38, fevereiro/2021, p. 272-290

Número Especial - III JOTA

www.revistas.usp.br/tradterm
} 
que acontece, por exemplo, com a inserção do tango e da Ferrari na peça. A transformação ou substituição, por sua vez, acontece quando "um elemento ou um segmento" do texto de partida, "mesmo mantendo algumas características inalteradas, muda outras" (INNOCENTI 2010: 37) e, por fim, a interpolação ocorre quando "segmentos do primeiro texto são simplesmente trocados de lugar, mas permanecem idênticos em si àqueles presentes no original" (2010: 83); essas duas últimas modalidades também estão presentes no processo de adaptação, pelo fato de os adaptadores terem utilizado um romance e dois filmes, encaixando os elementos de cada um nos outros e estruturando-os em um ritmo diferente.

Linda Hutcheon (2006: 29) reconhece adaptação como produto, vista como uma entidade formal, de natureza de "palimpsesto", e se caracteriza como "transposição anunciada e extensiva de uma ou mais obras". Nesse sentido, a autora reproduz Gérard Genette (2010: 7) que entende palimpsesto por:

um pergaminho cuja primeira inscrição foi raspada para se traçar outra, que não a esconde de fato, de modo que se pode lê-la por transparência, o antigo sob o novo. Assim, no sentido figurado, entenderemos por palimpsestos (mais literalmente: hipertextos) todas as obras derivadas de uma obra anterior, por transformação ou por imitação.

Quando uma obra é fruto da adaptação de outra obra, como, por exemplo, a peça teatral adaptação do romance e dos filmes é evidente que a peça tem correspondência com o livro e os filmes. Nas palavras de Genette (2010: 18), hipertextualidade é "toda relação que une um texto B [... hipertexto] a um texto anterior A [... hipotexto] do qual ele brota [...]. [É] uma noção geral de texto de segunda mão ou texto derivado de outro texto preexistente". Assim, o romance e os filmes são hipotextos e a peça hipertexto.

A autora reconhece, também, adaptação como processo de criação, afirmando que "a adaptação sempre envolve tanto uma (re-)interpretação quanto uma (re)criação" (HUTCHEON 2006: 29). Chamou-nos muito a atenção o fato de os adaptadores terem inserido elementos fílmicos no palco; a ideia cinematográfica dentro do teatro, por meio do videowall, fez com que os espectadores tivessem a

TradTerm, São Paulo, v.38, fevereiro/2021, p. 272-290

Número Especial - III JOTA

www. revistas.usp.br/tradterm 
sensação da viagem dos trens, do passeio com a Ferrari, das cidades por meio da projeção de fotografias e sons que remetiam a elas, para citar alguns exemplos.

Por fim, reconhece adaptação como processo de recepção, cuja forma é de intertextualidade, na qual se vivenciam "as adaptações (enquanto adaptações) como palimpsestos por meio da lembrança de outras obras que ressoam através da repetição com variação" (HUTCHEON 2006: 30, itálico da autora); os adaptadores, como vimos, se basearam em um livro e dois filmes para criarem a adaptação. Nesse sentido, se o espectador conhecer as outras obras - o romance, os filmes, ou ambos -, poderá identificá-las no espetáculo e, com isso, possivelmente enriquecer seu entendimento tanto sobre o(s) texto(s) fonte(s) quanto sobre o produto final. 0 espectador que não as conhece, por sua vez, não terá seu entendimento do espetáculo prejudicado e poderá, além disso, passar a conhecê-las por meio da adaptação.

TradTerm, São Paulo, v.38, fevereiro/2021, p. 272-290 Número Especial - III JOTA www. revistas.usp.br/tradterm 


\section{Referências}

ARPINo, G. Il Buio e il Miele, Romanzi e racconti, Baldini \& Castoldi Dalai, 1993.

ArPINo, G.; Marcari, R.; Risı, D. (adattamento di). Profumo di donna. Regia Dino Risi, 1974, colorato, 103 minuti.

Bahbout, N. The Scent of a Woman by Giovanni Arpino - Review. In: The Guardian, 12 de junho de 2011. Disponível em: https://www.theguardian.com/books/2011/jun/12/scent-of-a-womanreview. Acesso em: 15/01/2021.

BAY-CHENG et al (ed.). Mapping Intermediality in Performance. Amsterdam University Press: Amsterdam, 2010.

Cluver, C. Estudos Interartes. Conceitos, Termos, Objetivos. Literatura e Sociedade. São Paulo, v. 2, n. 2. 1997. p. 37-55

Dinız, T. F. Literatura e Cinema: da Semiótica à Tradução Cultural. Editora UFOP: Ouro Preto, 1999.

Eco, U. Dire Quasi la Stessa Cosa: Esperienze di Traduzione. Milano: Studi Bompiani, 2007.

EsSER, A. (ed.). Midia Across Borders: Localizing TV, Film and Videogames. Routledge: New York, 2016.

Genette, G. Palimpsestos: a Literatura de Segunda Mão. Trad. Luciene Guimarães. Supervisão e revisão Sônia Queiroz. Belo Horizonte: Edições Viva Voz, 2010.

Goldman, B. (adapted by). Scent of a woman. Directed by Martin Brest, 1992, colour, 156 minutes.

HUtCHEON, L. A Theory of Adaptation. New York: Routledge, 2006.

INNOCENTI, L. La Scena Trasformata: Adattamenti Neoclassici di shakespeare. Pisa: Pacini Editore, 2010.

JAKOBSON, R. Lingüística e Comunicação. São Paulo: Cultrix, 1969

Kattenbelt, C. In: Intermediality in Theatre and Performance: Definitions, Perceptions and Medial Relationships. Cultural Studies Journal of Universitat Jaume I, v. 6, 2008, pp. 19-29

KeHR, D. Creeping Phoniness. In: Chicago Tribune, 23 de dezembro de 1992. Disponivel em: $\quad<w w w . c h i c a g o t r i b u n e . c o m / n e w s / c t-x p m-1992-12-23-9204260552-$ story.html>. Acesso em: 15/01/2021.

TradTerm, São Paulo, v.38, fevereiro/2021, p. 272-290

Número Especial - III JOTA

www.revistas.usp.br/tradterm 
Mandagli, F. Classico vc Remake - Profumo di donna. In: Civico20 News, 4 de junho de 2017. Disponível em:

<http:/ / www.bdtorino.eu/sito/stampa_immagini.php?id=24677\&data=4\%20Gi ugno\%202017\&pubblicazione=Articolo\%20scritto\%20da\%20Fabio\%20Mandagli>. Acesso em: 15/01/2021.

PavIS, P. Dicionário de Teatro. Tradução sob a direção de Jacob Guinsburg e Maria Lúcia Pereira. São Paulo: Perspectiva, 2008.

PlazA, J. Tradução Intersemiótica. $1^{\text {a }}$ ed. São Paulo: Perspectiva, 2003.

Stam, R. Beyond Fidelity: the dialogics of adaptation. In: NAREMORE, J. Film adaptation. New Jersey: Rutgers University, 2000

Recebido em: 15/04/2020

Aceito em: 22/12/2020

Publicado em fevereiro de 2021

TradTerm, São Paulo, v.38, fevereiro/2021, p. 272-290

Número Especial - III JOTA

www.revistas.usp.br/tradterm 